\title{
Loss Minimization by Partial SAZZ for High-Power Chopper
}

\author{
Yukinori Tsuruta*a) Member, Atsuo Kawamura* Fellow
}

(Manuscript received Dec. 19, 2013, revised April 22, 2014)

\begin{abstract}
Loss minimization is vital in high-power choppers for electric drive systems in automobiles. This paper describes the evaluation of partial turn-off behavior in IGBTs (Insulated Gate Bipolar Transistor) by ZVS (Zero Voltage $\underline{\text { Switching) }}$ without over-elimination based on Partial SAZZ (Snubber $\underline{\text { A }}$ ssisted Zero Voltage and Zero Current Transition). High power BTB (back to back) experiments using a $90 \mathrm{~kW} 3$-phase interleaved chopper derived the good characteristics of the Partial SAZZ method and compared them with those of the hard switching (Hard SW) method. The total switching loss of the main circuit, which accounted for $48 \%(674 \mathrm{~W})$ in Hard SW, reduced to $192 \mathrm{~W}$, a $72 \%$ reduction, in Partial SAZZ. The Partial SAZZ method obtained the highest efficiency of $97.42 \%$ at $30 \mathrm{~kW}, 1.82 \%$ higher than Hard SW (95.6\%) and the highest efficiency over the entire power region. This was verified through a load test and loss breakdown of up to $30 \mathrm{~kW}$ per phase.
\end{abstract}

Keywords: power converters for FCEV, soft switching, IGBT, automotive application

\section{Introduction}

Improvement of efficiency for DC-DC converter has been widely studied in the many fields of industry such as transportation, electric appliance, computer, electric power and high-tech industry. Mainly rapid advances in semiconductor power devices based on hard switching and high frequency have made it possible ${ }^{(1)-(3)}$. However these studies were discussed in comparatively small power region and there were few focused on DC-DC converter by soft switching for high power range in which recent application expanded for electric drive on eco-EV such as Hybrid electric vehicles (HEV), pure electric vehicles (EV) and fúel cell electric vehicles (FCEV) taking the place of conventional vehicles with internal combustion engine (ICE). Recent years improvement of efficiency based on soft switching topology has been mainly discussed aimed for high power range converters ${ }^{(4)(5)}$. Power rating of DC-DC converter for these electric drives on eco-EV reaches the range beyond 10 and $50 \mathrm{~kW}$ and high efficiency DC-DC choppers with 98-99\% are reported. Generally these high power DC choppers are designed as multi-phase interleaved converter. J-S Lai reported ultra high efficiency 4-phase buck-boost chopper based on coupled inductors and super-junction MOSFET with $99.2 \%$ at $30 \mathrm{~kW}^{(6)}$ and with $99 \%$ at $50 \mathrm{~kW}^{(7)}$. B. Eckard also developed 12-phase buck-boost chopper with 97-98\% range ${ }^{(8)}$. Hirakawa reported high efficiency 2-phase buck-boost chopper based on coupled inductors with $98.4 \%$ at $42 \mathrm{~kW}^{(9)}$.

Based on "Verification of Efficient Operation for High Power DC Chopper" by Yukinori Tsuruta and Atsuo Kawamura which appeared in the proceedings of the 8th International Conference on Power Electronics - ECCE Asia, (c)2011 IEEE.

a) Correspondence to: Yukinori Tsuruta. E-mail: tsuruta@ynu.ac .jp

* Department of Electrical and Computer Engineering, Faculty of Engineering, Yokohama National University

79-5, Tokiwadai, Hodogaya-ku, Yokohama 240-8501, Japan
The authors have been studying the improvement of efficiency by soft switching topology. C-Bridge switch shown in Fig. 1(a) was proposed ${ }^{(10)}$ with $8 \mathrm{~kW}, 25 \mathrm{kHz}$ and 96.0\%. Later on, Quasi-resonant Regenerating Active Snubber (QRAS) chopper shown in Fig. 1(b) was originally proposed $^{(11)}$ to achieve zero current switch (ZCS) turn-on and ZVS turn-off by regenerating the snubber energy to DC reactor divided in two parts to improve efficiency of C-Bridge switch. The efficiency was improved from $96.0 \%$ to $97.5 \%$ at $8 \mathrm{~kW}, 25 \mathrm{kHz}$. The improvement of efficiency was further obtained by SAZZ topology shown in Fig. 1(c) ${ }^{(12)(13)}$. The efficiency was improved from $97.5 \%$ to $99.0 \%$ at $8 \mathrm{~kW}$, $25 \mathrm{kHz}^{(14)}$. Moreover the authors have studied $30 \mathrm{kHz}$ prototype model of 3-phase interleaved boost chopper created by SAZZ topology for FCEV high power application from 2007 fiscal year. However following points proved problems of conventional SAZZ method for high power application. 1) Surge voltage across auxiliary switch $\mathrm{S}_{2}$ appeared big due to high power operation of conventional SAZZ chopper ${ }^{(15)}$. 2) Snubber capacitance tends to be bigger to keep perfect ZVS

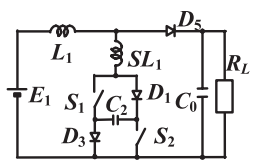

(a) C-bridge ${ }^{(10)}$

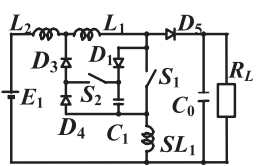

(b) QRAS ${ }^{(11)}$

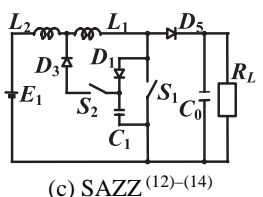

Fig. 1. High efficiency soft switching topologies 
condition during turn-off due to high power operation and total efficiency decreases. Partial SAZZ method that could be revised from conventional SAZZ to minimize total loss ${ }^{(16)}$. In chapter 2 principle of SAZZ chopper, theory of partial soft switching method as Partial SAZZ design and efficiency sensitivity analysis on SAZZ topology will be showed. Test verification by the $30 \mathrm{kHz}$ prototype model chopper will be discussed in chapter 3. Chapter 4 is conclusion.

\section{3-Phase Interleaved SAZZ Chopper}

As a basic concept, to combine advantages of soft switching and plural parallel connections of power converter new three-phase interleaved chopper is created by single basic SAZZ chopper. Comparing with conventional topology, downsizing of input smoothing capacitor due to the reduction of ripple current is expected as advantage of multi-phase topology. At the same time higher efficiency is expected to be obtained by advantage of soft switching topology SAZZ.

2.1 Circuit Topology by 3-phase Interleaved Concept

Figure 2 shows a new three-phase interleaved SAZZ chopper. The main part of the single phase has simple

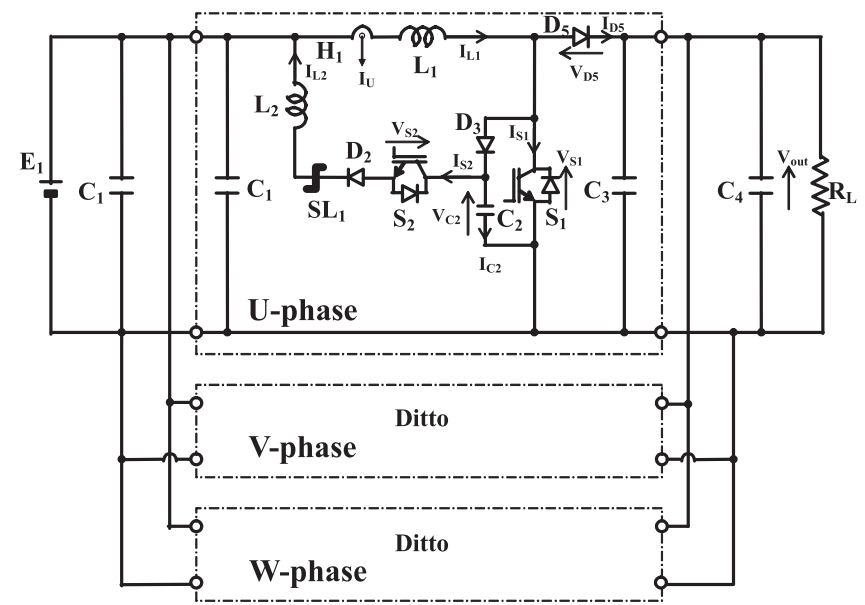

Fig. 2. Three phase interleaved SAZZ chopper configuration of 2 switches $\left(S_{1}\right.$ and $\left.S_{2}\right), 3$ diodes $\left(D_{2}, D_{3}\right.$, and $\left.D_{5}\right), 2$ reactors $\left(L_{1}\right.$ and $\left.L_{2}\right)$ and 3 capacitors $\left(C_{1}, C_{2}\right.$, and $\mathrm{C}_{3}$ ). This configuration retains the desirable properties of the low turn on switching loss and low turn off switching loss so called a "soft switching".

2.2 Principle of Operation To explain theoretically the operational principles, duty $\mathrm{D}=0.5$ is assumed in following explanation. Figure 3 shows the operational waveforms and Fig. 4 shows the equivalent circuits corresponding to 6 operational modes of U-phase on SAZZ topology. Each phase such as U-phase, V-phase and W-phase has $120^{\circ}$ phase shift, which is equivalent to a $1 / 3$ period of operational switching frequency.

1) Mode 1: Pre-turn-on

Main current through main reactor $\mathrm{L}_{1}$ flows during Mode $6\left(\mathrm{t}<-\mathrm{t}_{2}\right)$ shown in Fig. 4(f). At $\mathrm{t}=-\mathrm{t}_{2}$ auxiliary switch $S_{2}$ turns on earlier than $S_{1}$. Current through auxiliary switch $\mathrm{S}_{2}$ increase in the loop (+) $\mathrm{C}_{3}-\mathrm{D}_{5}-\mathrm{D}_{3}-\mathrm{S}_{2}-\mathrm{D}_{2}-\mathrm{SL}_{1}-\mathrm{L}_{2}-(+) \mathrm{C}_{1}$ at the rate of $\left(V_{\text {out }}-E_{1}\right) t / L_{2}$. So auxiliary switch $S_{2}$ turns on

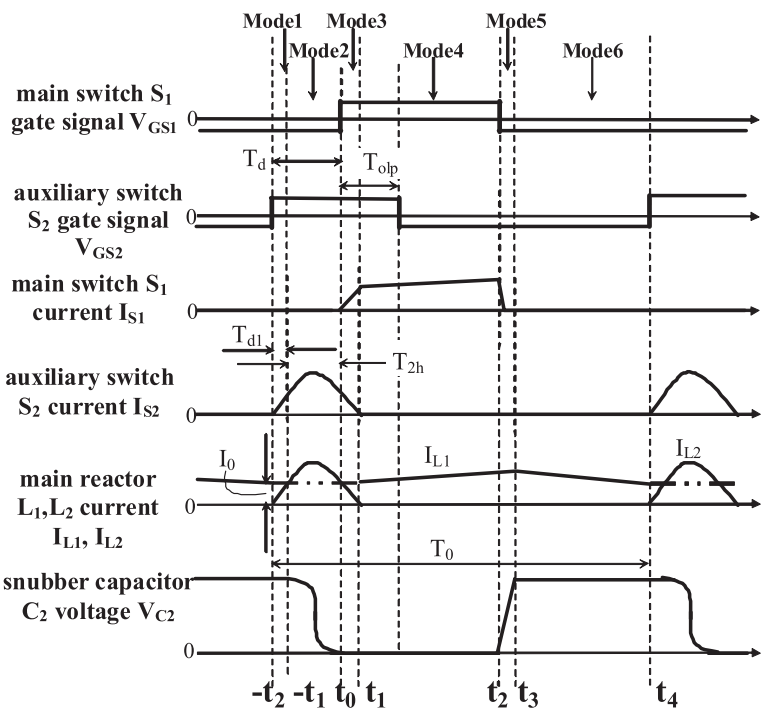

Fig. 3. Operating waveforms for SAZZ boost configuration

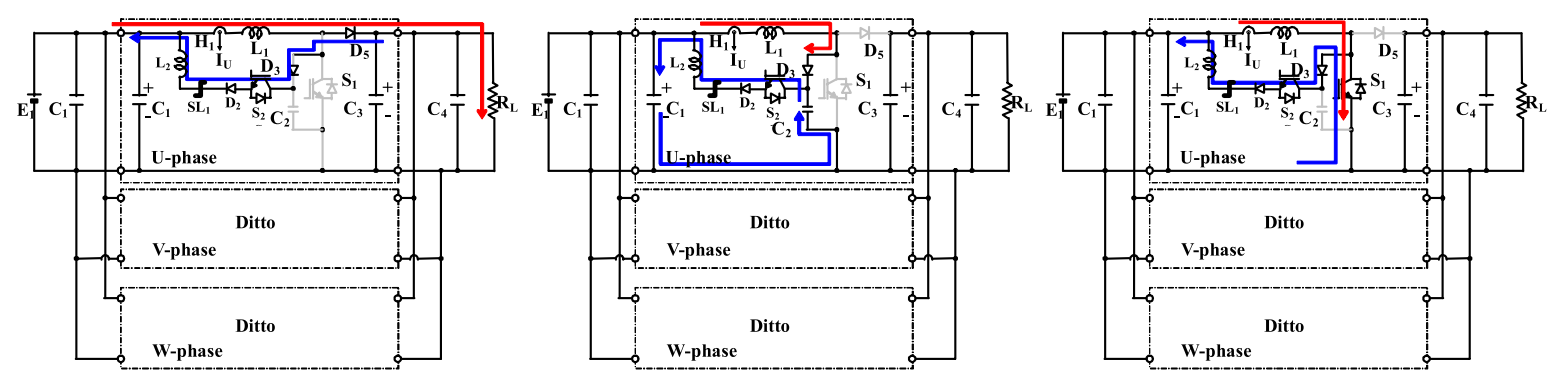

(a) Mode 1

(b) Mode 2

(c) Mode 3

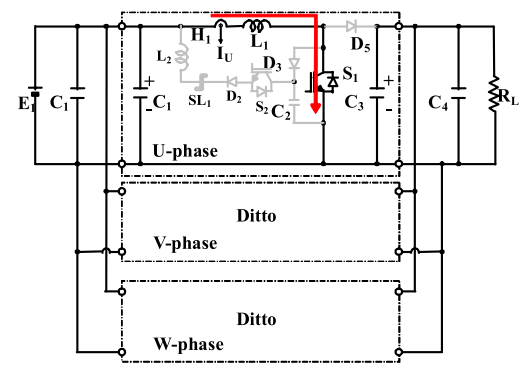

(d) Mode 4

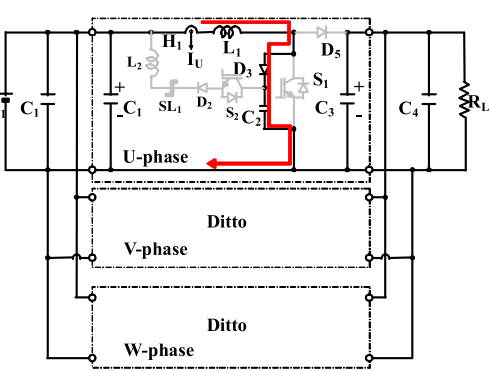

(e) Mode 5

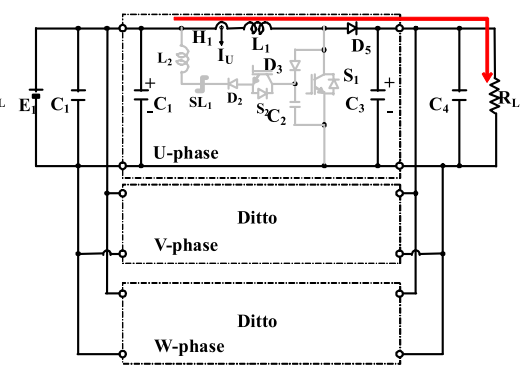

(f) Mode 6

Fig. 4. Equivalent circuits in six operational modes 
from zero current. When current through auxiliary switch $S_{2}$ reaches load current value $I_{0}$ at $t=-t_{1}$, output diode $D_{5}$ turns off due to the reverse recovery of $\mathrm{D}_{5}$. Mode 1 ends as shown in Fig. 4(a).

2) Mode 2: Discharging snubber $C_{2}$

When $\mathrm{D}_{5}$ turns off at $\mathrm{t}=-\mathrm{t}_{1}$ in Mode 1 , main current through main reactor $\mathrm{L}_{1}$ flows in the loop $\mathrm{L}_{1}-\mathrm{D}_{3}-\mathrm{S}_{2}-\mathrm{D}_{2}-\mathrm{SL}_{1}$ $\mathrm{L}_{2}-\mathrm{L}_{1}$. Simultaneously, at $\mathrm{t}=-\mathrm{t}_{1}$ voltage $\mathrm{V}_{\mathrm{C} 2}$ across snubber capacitor $\mathrm{C}_{2}$ begins to discharge in resonant mode such as sinusoidal wave change from plus to zero. When voltage $V_{C 2}$ across snubber capacitor $\mathrm{C}_{2}$ become zero at $\mathrm{t}=\mathrm{t}_{0}$. Mode 2 ends as shown in Fig. 4(b).

3) Mode 3: Turn-on with canceling main current of main switch $S_{1}$

When voltage $V_{C 2}$ across snubber capacitor $C_{2}$ becomes zero at $\mathrm{t}=\mathrm{t}_{0}$ in Mode 2, simultaneously, main switch $\mathrm{S}_{1}$ turns on. $\mathrm{I}_{\mathrm{L} 1}$ keeps constant $\mathrm{I}_{0}$ due to very short transient period. Since $\mathrm{I}_{\mathrm{L} 2}$ decrease from initial current $\mathrm{I}_{0}$ in the loop of (-) $\mathrm{C}_{1^{-}}$ $\mathrm{S}_{1}-\mathrm{D}_{3}-\mathrm{S}_{2}-\mathrm{D}_{2}-\mathrm{SL}_{1}-\mathrm{L}_{2}-\mathrm{C}_{1}(+)$ shown in Fig. 4(c), $\mathrm{I}_{\mathrm{S} 1}\left(=\mathrm{I}_{0}-\mathrm{I}_{\mathrm{L} 2}\right)$ increase from zero current. So at $t=t_{0}$ main switch $S_{1}$ turns on in zero voltage and zero current. Store energy of reactor $\mathrm{L}_{2}$ is under regenerating state as shown in Fig. 4(c). When regenerating current through auxiliary switch $S_{2}$ decrease to zero at $\mathrm{t}=\mathrm{t}_{1}$, Mode 3 ends.

4) Mode 4: On state

From $\mathrm{t}=\mathrm{t}_{1}$ to $\mathrm{t}=\mathrm{t}_{2}$ current through reactor $\mathrm{L}_{1}$ builds up as shown in Fig. 4(d).

5) Mode 5:turn-off of main switch $S_{1}$

At $\mathrm{t}=\mathrm{t}_{2}$ the voltage across main switch $\mathrm{S}_{1}$ is snubbed by the capacitor $\mathrm{C}_{2}$ as shown in Fig. 4(e).

6) Mode 6:off-state

Switches are all in off state as shown in Fig. 4(f).

2.3 Principle of Partial SAZZ Operation (17) "Partial SAZZ operation" is method to improve total efficiency of soft switching chopper as proposed in this paper. Snubber capacitor $\mathrm{C}_{2}$ is charged by current $\mathrm{I}_{\mathrm{L} 1}$ during ZVS turn-off using $\mathrm{C}_{2} \mathrm{D}_{3}$ snubber shown in Fig. 4(e). Fig. 5 shows principal waveforms of ZVS turn-off without consideration of wiring inductance and tail current. In following approximation, tail current is neglected because it is not published as device data in catalogue. Therefore turn off loss $\mathrm{P}_{S 1 \_o f f}$ during fall time $t_{f}$ of main IGBT $S_{1}$ becomes substantially negligible small according to the increase of turn-off speed of main IGBT $S_{1}$. This justifies the design of decreasing value of capacitance $\mathrm{C}_{2}$ using $\mathrm{C}_{2} \mathrm{D}_{3}$ snubber as "partial ZVS turn-off" in order to improve total efficiency reducing loss of the auxiliary circuit. Fig. 6 shows normalized operating area of analysis model of SAZZ chopper shown in Fig. 2. Efficiency sensitivity analysis is calculated at highest loss point $\mathrm{A}$ in normalized operating area. Under the condition of this point $A$, equations of circuit component loss are calculated under Partial SAZZ operation mentioned above. Table 1 shows the definition of symbols regarding loss equations.

In terms of loss factor of IGBT $S_{1}$ first equation of total loss $P_{S 1 \_t o t a l}$ is derived approximately from

$$
\begin{aligned}
P_{S 1 \_t o t a l} & =P_{S 1 \_o n}+P_{S 1 \_o n-s t a t e}+P_{S 1 \_o f f} \\
& =V_{S 1 \_C E s a t} \times I_{L 1 \_a v} \times\left(1-\frac{E_{1}}{V_{\text {out }}}\right)+\frac{1}{6} I_{\text {off }} V_{t f} t_{f} f
\end{aligned}
$$

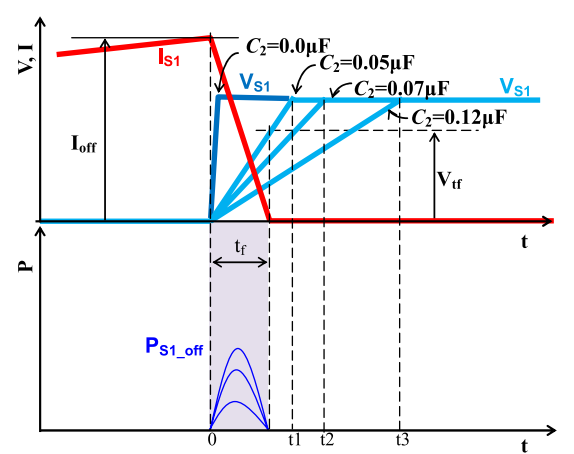

Fig. 5. Partial soft switching by ZVS turn off

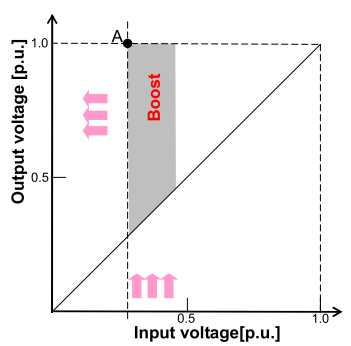

Fig. 6. Normalized operating area

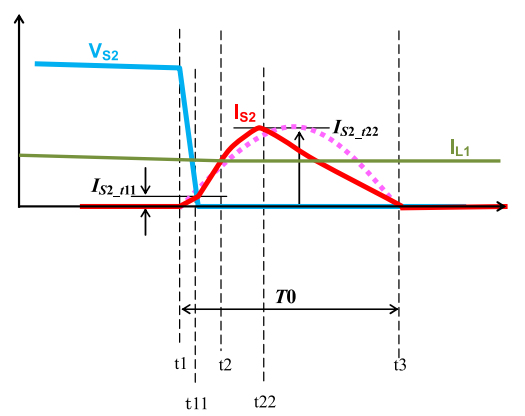

Fig. 7. Sinusoidal approximation of current waveform on auxiliary IGBT $\mathrm{S}_{2}$

where $\mathrm{P}_{\mathrm{S} 1 \_ \text {on }}$ can be neglected by zero voltage and zero current switching (ZVZCS).

Total loss $P_{D 5 \_t o t a l}$ of output diode $\mathrm{D}_{5}$ becomes

$$
\begin{aligned}
P_{D 5 \_t o t a l} & =P_{D 5 \_V F}+P_{D 5 \_t r r} \\
& =V_{D 5 \_V F} \times I_{L 1 \_a v} \times \frac{E_{1}}{V_{\text {out }}}+f \times Q_{D 5 \_t r r} \times V_{D 5 \_r}[W]
\end{aligned}
$$

By sum of (1), (2) total loss of main IGBT module $P_{S 1 \_ \text {module }}$ is as follows

$$
\begin{aligned}
& P_{S 1 \_ \text {module }}=P_{S 1 \_t o t a l}+P_{D 5 \_t o t a l} \\
& =V_{S 1 \_C E s a t} \times I_{L 1 \_a v} \times\left(1-\frac{E_{1}}{V_{\text {out }}}\right)+\frac{1}{6} I_{\text {off }} V_{t f} t_{f} f \\
& \quad+V_{D 5 \_V F} \times I_{L 1 \_a v} \times \frac{E_{1}}{V_{\text {out }}}+f \times Q_{D 5 \_t r r} \times V_{D 5 \_r}[W]
\end{aligned}
$$

where $S_{1}$ and $D_{5}$ are included in one module.

Based on sinusoidal approximation of current waveform shown in Fig. 7, total loss of auxiliary IGBT $\mathrm{S}_{2} P_{S 2 \_t o t a l}$ becomes

$$
P_{S 2 \_t o t a l}=P_{S 2 \_ \text {on }}+P_{S 2 \_ \text {on-state }}
$$


Table 1. Definition of symbols

\begin{tabular}{|c|c|c|c|}
\hline $\mathrm{E}_{1}$ & Input DC power source voltage & $\mathrm{T}_{\text {period }}$ & Period \\
\hline $\mathrm{V}_{\text {out }}$ & Output voltage & $\mathrm{V}_{\mathrm{tf}}$ & Voltage of snubber $\mathrm{C}_{2}$ at $\mathrm{t}=\mathrm{tf}$ \\
\hline $\mathrm{L}_{1}$ & Inductance of main reactor & tc & Charging time of snubber $\mathrm{C}_{2}$ \\
\hline $\mathrm{L}_{2}$ & Inductance of auxiliary reactor & tf & Fall time of IGBT $\mathrm{S}_{\|}$ \\
\hline $\mathrm{C}_{2}$ & Capacitance of snubber capacitor & $\operatorname{tr}$ & Rise time of IGBT S \\
\hline $\mathrm{C}_{3}$ & Capacitance of output smoothing capacitor & $t_{\mathrm{rr}}$ & Reverse recovery time \\
\hline $\mathrm{R}_{\mathrm{L}}$ & Load resistance & $\omega_{0}$ & Resonant angular frequency \\
\hline $\mathrm{P}_{\text {out }}$ & Output power & $\eta$ & Efficiency \\
\hline$\overline{I_{\text {off }}}$ & Peak current of $\mathrm{I}_{\mathrm{S} 1}$ at turn-off of $\mathrm{S}_{1}$ & $\mathrm{D}$ & Duty \\
\hline $\mathrm{V}_{\mathrm{DH}-\mathrm{VF}}$ & Forward voltage drop of diode $\mathrm{D}_{\#}$ & $\mathrm{f}$ & Switching frequency \\
\hline $\mathrm{V}_{\mathrm{S} \# \text { CEsat }}$ & Saturation C-E voltage of switch $\mathrm{S}_{\#}$ & 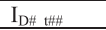 & Current of diode $\mathrm{D}_{\# \text { at }}$ t $=\mathrm{t}_{\# \#}$ \\
\hline $\mathrm{I}_{\mathrm{S} \#}$ & Current of switch $S_{\#}$ & $\mathrm{I}_{0}$ & Initial value of current $I_{S 1}$ at $S_{1}$ turn on \\
\hline$I_{S \# \text { t\#\# }}$ & Current of switch $\mathrm{S}_{\# \text { at }} \mathrm{t}=\mathrm{t}_{\# \#}$ & $\mathrm{~V}_{\mathrm{S} \# \text { CEsat }}$ & Corrector-Emitter saturation voltage of $\mathrm{S}_{\#}$ \\
\hline$P_{S \# \text { off }}$ & Turn off loss of IGBT $S_{\#}$ & $\mathrm{~V}_{\mathrm{D} / \mathrm{SH} \mathrm{VF}}$ & Forward on voltage of reverse parallel diode of $\mathrm{S}_{\#}$ \\
\hline $\mathrm{P}_{\mathrm{S} \# \text { on-state }}$ & On-state loss of IGBT S $S_{\#}$ & $\mathrm{~V}_{\mathrm{D} / \mathrm{S} \# \mathrm{r}}$ & Reverse voltage of $\mathrm{S}_{\| \#}$ \\
\hline $\mathrm{P}_{\mathrm{S} \# \text { total }}$ & Total loss of IGBT $S_{\#}$ & $\mathrm{I}_{\mathrm{Ll} \text { av }}$ & Average current of reactor $\mathrm{L}_{1}$ \\
\hline $\mathrm{P}_{\mathrm{S} \# \text { module }}$ & Total loss of $\mathrm{S}_{\#}$ module (IGBT $\mathrm{S}_{\#}$ and anti-parallel diode of $\mathrm{S}_{\#}$ ) & $\mathrm{Q}_{\mathrm{D} / \mathrm{SH} \text { trr }}$ & Recovery charge of reverse parallel diode of $\mathrm{S}_{\#}$ \\
\hline $\mathrm{P}_{\mathrm{D} / \mathrm{SH}} \mathrm{VF}$ & Forward on state loss of anti-parallel diode of $\mathrm{S}_{\#}$ & $\mathrm{P}_{\mathrm{SL1} 1}$ & Core loss of saturable reactor $\mathrm{SL}_{1}$ \\
\hline $\mathrm{P}_{\mathrm{D} / \mathrm{S} \# \text { trr }}$ & Recovery loss of anti-parallel diode of $\mathrm{S}_{\#}$ & $\mathrm{P}_{\mathrm{L \#}}$ & Total loss of reactor $\mathrm{L}_{\#}$ \\
\hline $\mathrm{P}_{\mathrm{D} / \mathrm{SH} \text { total }}$ & Total loss of anti-parallel diode of $\mathrm{S}_{\#}$ & $V_{D \# V F}$ & Forward voltage of diode $\mathrm{D}_{\#}$ \\
\hline $\mathrm{T}_{0}$ & Time width of current flow of $S_{2}$ & $\mathrm{Q}_{\mathrm{DH} \text { trr }}$ & Recovery charge of diode $\mathrm{D}_{\#}$ \\
\hline $\mathrm{P}_{\mathrm{D \#} \text { on-state }}$ & On-state loss of $\mathrm{D}_{\#}$ & $\mathrm{P}_{\mathrm{D} \# \text { trr }}$ & Recovery loss of diode $\mathrm{D}_{\#}$ \\
\hline $\mathrm{P}_{\mathrm{D} \# \text { total }}$ & Total loss of $\mathrm{D}_{\#}$ & 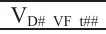 & Forward voltage of diode $\mathrm{D}_{\#}$ at $\mathrm{t}_{\# \#}$ \\
\hline $\mathrm{P}_{\mathrm{SAZZ}}$ & Total loss of SAZZ chopper & di $/ \mathrm{dt}_{\mathrm{t} \#}$ & Decrease rate of current per unit second at $t_{\#}$ \\
\hline
\end{tabular}

$$
=\frac{1}{6} I_{S 2 \_t 11}\left(V_{\text {out }}-\mathrm{E}_{1}\right) t_{\mathrm{r}} f+\frac{2}{\pi} V_{S 2 \_C E s a t} I_{S 2 \_t 22} \frac{T_{0}}{T_{\text {period }}}[W]
$$

where peak current $\mathrm{I}_{\mathrm{S} 2 \_t 22}$ of current $\mathrm{I}_{\mathrm{S} 2}$ is as follows

$$
I_{S 2 \_t 22}=I_{L 1 \_a v} \frac{0.6}{0.8}+\left(V_{\text {out }}-E_{1}\right) \sqrt{\frac{C_{2}}{L_{2}}} \ldots \ldots \ldots \ldots
$$

Total loss of auxiliary diode $\mathrm{D}_{2} P_{D 2 \_t o t a l}$ is as follows

$$
\begin{aligned}
P_{D 2 \_t o t a l}= & P_{D 2 \_ \text {on-state }}+P_{D 2 \_t r} \\
= & \frac{2}{\pi} V_{D 2 \_V F} \times I_{D 2 \_t 22} \times \frac{T_{0}}{T_{\text {period }}}+f \times \frac{-d i / d t_{\_t 4}}{-d i / d t_{-t y p}} \\
& \times Q_{D 2 \_t r \_\_t y p} \times E_{1} \cdots \cdots \cdots \cdots \cdots \cdots(6)
\end{aligned}
$$

By similar approximation total loss of snubber diode $P_{D 3 \_ \text {on-state }}$ is expressed by

$$
\begin{aligned}
& P_{D 3 \_ \text {on-state }}=\frac{2}{\pi} V_{D 3 \_V F \_t 22} \times I_{D 3 \_t 22} \\
& \times \frac{T_{0}}{T_{\text {period }}}+\frac{2}{\pi} \times V_{D 3 \_V F \_c} \times I_{\text {off }} \times \frac{t_{C}}{T_{\text {period }}}[W]
\end{aligned}
$$

Total loss $P_{S A Z Z}$ is given by (3), (4), (6), (7)

$$
\begin{aligned}
P_{S A Z Z}= & P_{S 1 \_ \text {module }}+P_{S 2 \_t t a l}+P_{D 2 \_t t a l}+P_{D 3 \_t o t a l} \\
& \left.+P_{S L 1}+P_{L 1}+P_{L 2} \ldots \ldots \ldots \ldots \ldots \ldots \ldots\right)(8)
\end{aligned}
$$

Total efficiency $\eta$ is calculated by

$$
\eta=\frac{P_{\text {out }}}{P_{\text {out }}+P_{S A Z Z}}=\frac{30 k W}{30 k W+P_{S A Z Z}}[\%]
$$

2.4 Efficiency Sensitivity Analysis Table 2 shows normal parameter for sensitivity analysis at point $\mathrm{A}$. Effi-

\begin{tabular}{|c|c|c|c|}
\hline Parameter & Symbol & unit & A \\
\hline Input voltage & E1 & {$[\mathrm{V}]$} & $0.277^{*}$ \\
\hline Output voltage & $\mathrm{V}_{\text {out }}$ & [V] & $1.0^{*}$ \\
\hline Operating frequency & $\mathrm{f}$ & {$[\mathrm{kHz}]$} & 30.0 \\
\hline Rise time of IGBT S & $\operatorname{tr}$ & {$[\mathrm{ns}]$} & 100 \\
\hline Saturation C-E voltage of switch $\mathrm{S}_{2}$ & $\mathrm{~V}_{\mathrm{S} 2 \text { CEsat }}$ & {$[\mathrm{V}]$} & 1.75 \\
\hline Forward voltage drop of diode $D_{3}$ & \begin{tabular}{|l|l|l}
$V_{D 3-V F}$ \\
\end{tabular} & {$[\mathrm{~V}]$} & 2.6 \\
\hline $\begin{array}{l}\text { Recovery charge of reverse parallel } \\
\text { diode of } S_{1}\end{array}$ & $Q_{D / S 1 \text { trm }}$ & {$[\mu \mathrm{C}]$} & 2.287 \\
\hline Capacitance of snubber capacitor & $\mathrm{C}_{2}$ & {$[\mu \mathrm{F}]$} & 0.05 \\
\hline Duty & $\mathrm{D}$ & & 0.5 \\
\hline Inductance of auxiliary reactor $\mathrm{L}_{2}$ & $\begin{array}{ll}\mathrm{L}_{2} \\
\mathrm{n}\end{array}$ & {$[\mu \mathrm{H}]$} & 0.45 \\
\hline Rise time of IGBT $\mathrm{S}_{1}$ & tr & {$[\mathrm{ns}]$} & 100 \\
\hline Saturation C-E voltage of switch $\mathrm{S}_{1}$ & \begin{tabular}{|l|}
$V_{S 1 C E s a t}$ \\
\end{tabular} & {$[\mathrm{~V}]$} & 1.6 \\
\hline Fall time of IGBT $S_{1}$ & tf & {$[\mathrm{ns}]$} & 100 \\
\hline Peak current of $I_{\mathrm{S} 1}$ at turn-off of $S_{1}$ & $\mathrm{I}_{\text {off }}$ & {$[\mathrm{A}]$} & 212.5 \\
\hline Average current of reactor $\mathrm{L}_{1}$ & $\mathrm{I}_{\mathrm{LI} \text { an }}$ & {$[\mathrm{A}]$} & 170 \\
\hline Forward voltage of diode $D_{2}$ & $\mathrm{~V}_{\mathrm{D} 2 \mathrm{VF}}$ & {$[\mathrm{V}]$} & 4.5 \\
\hline Recovery charge of diode $D_{2}$ & $\mathrm{Q}_{\mathrm{D} 2 \text { trit tvo }}$ & {$[\mu \mathrm{C}]$} & 28 \\
\hline Resonant angular frequency & $\omega_{0}$ & & $6.67 \mathrm{e}+6$ \\
\hline
\end{tabular}
ciency sensitivity by shifting $\mathrm{C}_{2}$ parameter $\pm \Delta \mathrm{C}_{2}$ from normal value of snubber capacitance $C_{2}$ in Table 2 is calculated. Figure 8 shows result of efficiency sensitivity analysis by change of resonant snubber $\mathrm{C}_{2}$. Normal value $0.05 \mu \mathrm{F}$ of snubber capacitance $\mathrm{C}_{2}$ is approximately optimum and highest efficiency is obtained. Figure 9 shows result of efficiency sensitivity analysis by shifting $\mathrm{L}_{2}$ parameter $\pm \Delta \mathrm{L}_{2}$ from normal value of auxiliary inductance $\mathrm{L}_{2}$ in Table 2. Normal
Table 2. Normal parameter for sensitivity analysis

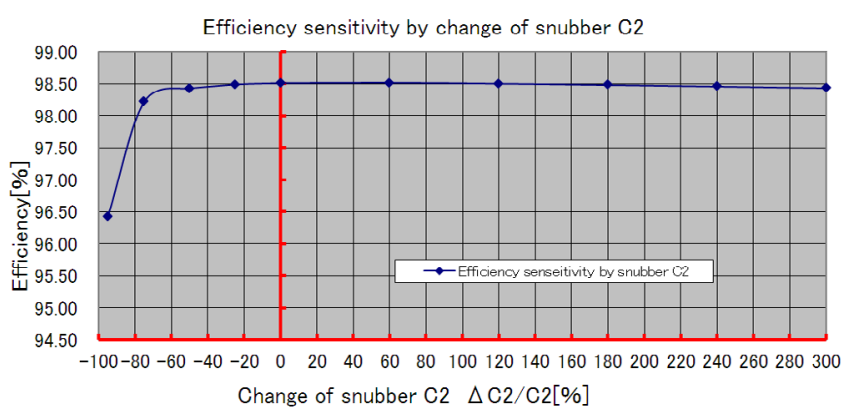

Fig. 8. Efficiency sensitivity by change of resonant snubber $\mathrm{C}_{2}$

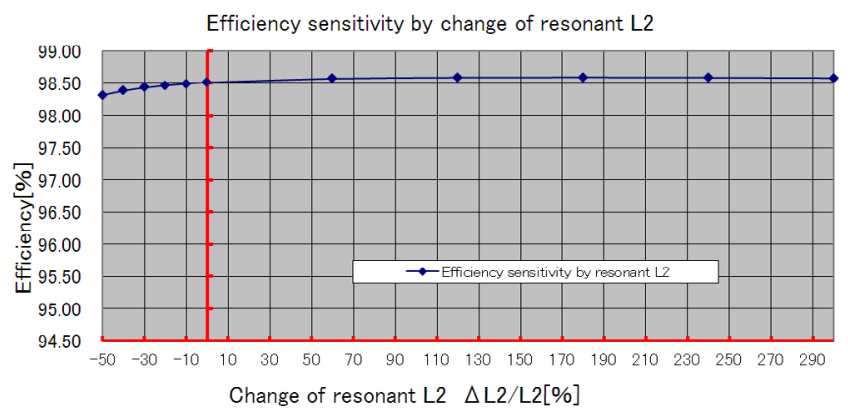

Fig. 9. Efficiency sensitivity by change of resonant $\mathrm{L}_{2}$ 
value $0.45 \mu \mathrm{H}$ of auxiliary inductance $\mathrm{L}_{2}$ is considered nearly optimum. Total inductance of auxiliary circuit depends on the fixed structure of wiring method. Since value of inductance $\mathrm{L}_{2}$ is hard to vary freely, as a result of analysis, it is considered that resonant $\mathrm{L}_{2} \mathrm{C}_{2}$ parameter optimized is approximately $\mathrm{L}_{2}=0.45 \mu \mathrm{H}$ and $\mathrm{C}_{2}=0.05 \mu \mathrm{F}$.

\section{Experimental Results}

3.1 Back to Back Test System for High Power Chopper Experiment was performed by back to back test system shown in Fig. 10. Figure 10 shows $60 \mathrm{~kW}$ back-to-back (BTB) converter test setup. Only one chopper unit of $30 \mathrm{~kW}$ per phase was operated as tested converter at operating frequency of $30 \mathrm{kHz}$. Verification was under $30 \mathrm{~kW}$ at input $200 \mathrm{~V} /$ output $400 \mathrm{~V}$ at $30 \mathrm{kHz}$. In the input side $2 \mathrm{DC}$ power sources APL-II \#1 and \#2 with $10 \mathrm{~kW}$ are operated in masterslave run. The output power of tested converter is regenerated back through DC power controller $(60 \mathrm{~kW}$ Power Adjustment Controller: PAC). The description on exterior of $90 \mathrm{~kW}$ prototype is omitted due to industrial secret.

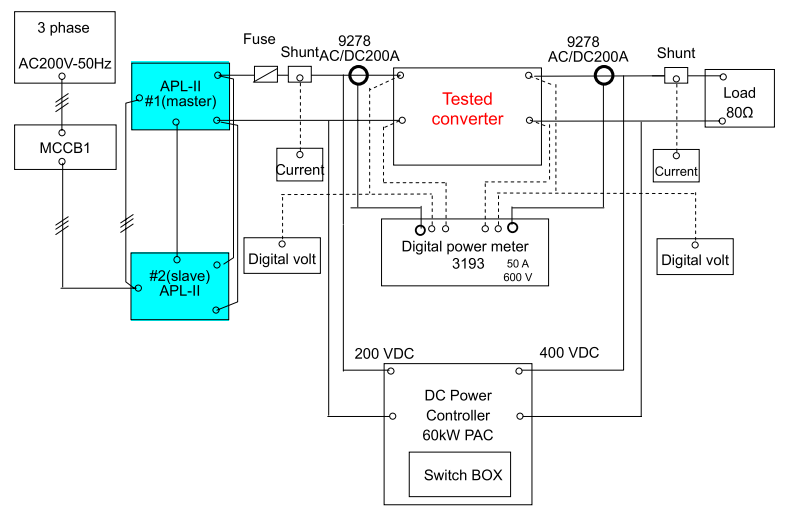

Fig. 10. Back to Back test system for high power chopper

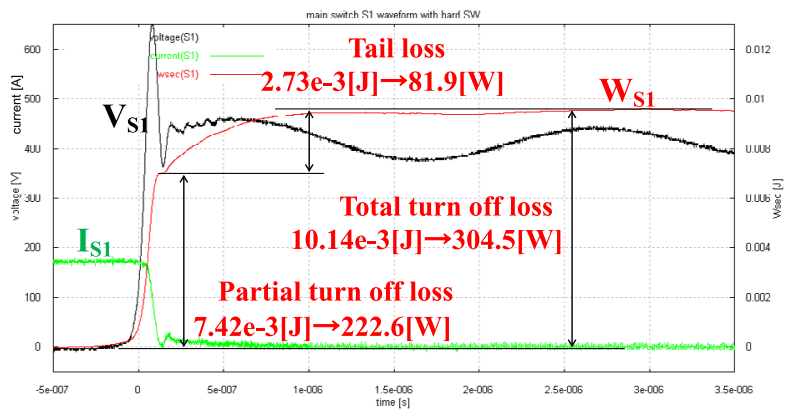

(a) Conventional Hard SW

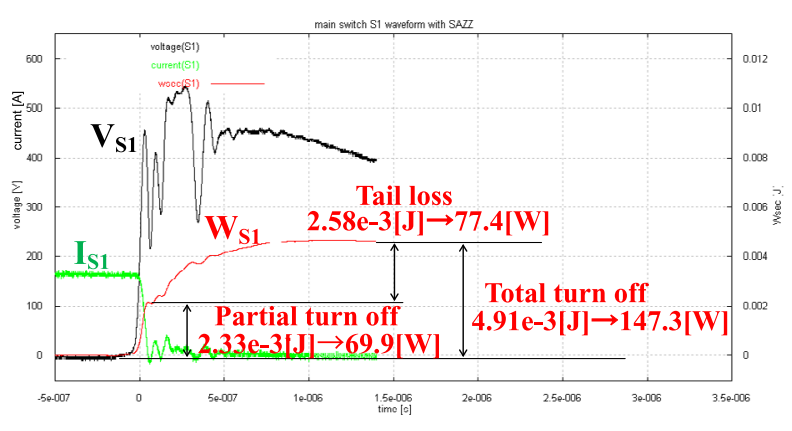

(b) Partial SAZZ

Fig. 11. Turn-off loss of main IGBT $\mathrm{S}_{1}$ when $30 \mathrm{~kW}$
3.2 Comparison of Turn off Switching Loss with Hard SW The waveforms are obtained under switching frequency $\mathrm{f}_{\mathrm{s}}=30 \mathrm{kHz}$, the output power $\mathrm{P}=30 \mathrm{~kW}$, boost mode: $\mathrm{V}_{\text {in }}=200 \mathrm{~V}, \mathrm{~V}_{\text {out }}=400 \mathrm{~V}$. The comparison of turn-off experimental waveforms is shown in Fig. 11. Figure 11(a) shows conventional Hard SW, Fig. 11(b) shows Partial SAZZ. By means of partial ZVS total turn off loss of main switch $S_{1}$ decrease $304.5 \mathrm{~W}$ (Hard SW) $\rightarrow 147.3 \mathrm{~W}$ (Partial SAZZ) with $51.6 \%$ reduction. The first half of ZVS turn off decrease 222.6 W (Hard SW) $\rightarrow$ 69.9 W (Partial SAZZ) with $68.6 \%$ reduction. Tail loss in the second half decrease $81.9 \mathrm{~W}$ (Hard SW) $\rightarrow 77.4 \mathrm{~W}$ (Partial SAZZ) with $5.5 \%$ reduction. Comparing Partial SAZZ to Hard sw, the first half of ZVS turn off loss can be reduced. Total turn-off loss reduces $87 \%$ from 304.5 W (Hard SW) to 147.3 W (Partial SAZZ).

3.3 Comparison of Efficiency with Hard SW The efficiency measurement was carried out by comparing between conventional Hard SW and Partial SAZZ through 1$30 \mathrm{~kW}$ at $200 \mathrm{~V} / 400 \mathrm{~V}$ at $30 \mathrm{kHz}$ by Hioki digital power meter 3193, cramp on unit: 9602 + current sensor: 9278200 A. Figure 12 shows the result of efficiency measurement for the complete load range. As can be seen, at $30 \mathrm{~kW}$ Partial SAZZ was $1.82 \%$ higher than Hard SW, from $95.6 \%$ to $97.42 \%$.

\subsection{Comparison of Total Loss Breakdown with Hard} SW All waveforms of all power devices separately measured for each switching states were analysed to obtain loss breakdown by each circuit topologies. On state loss was measured by high precision differential amplifier Lecroy DA1855A, probe Lecroy DXC100A and digital oscilloscope Lecroy WAVEPRO 950. Figure 13 shows total loss breakdown by circuit topologies. Total main circuit switching loss decreases 674.2 W (Hard SW) $\rightarrow 191.8$ W (Partial SAZZ)

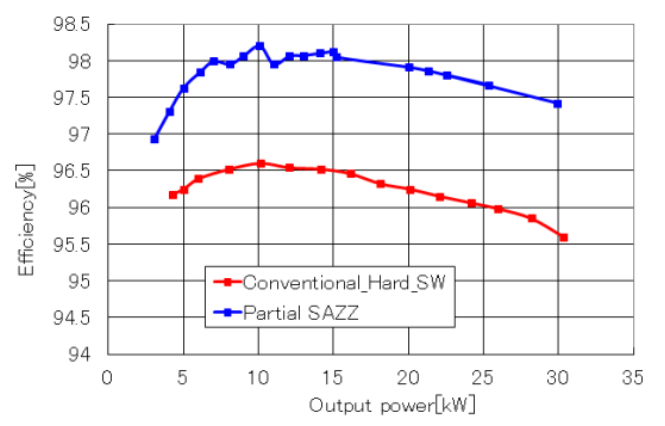

Fig. 12. Efficiency characteristics versus output power

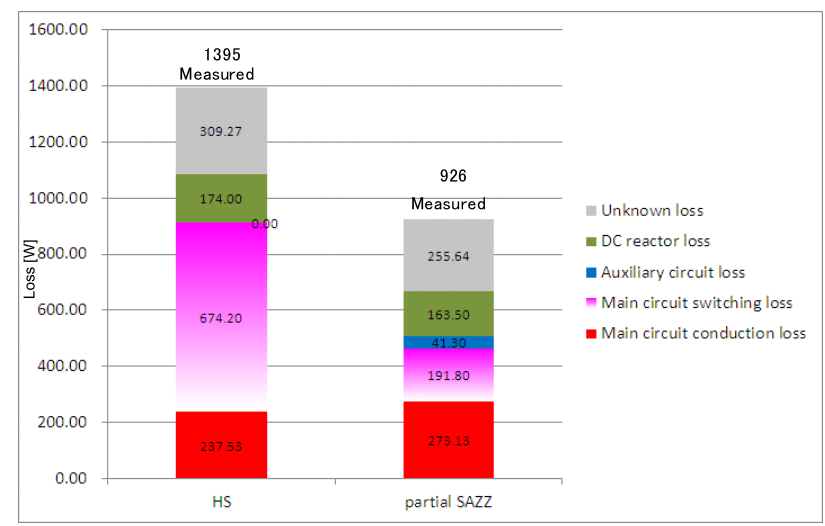

Fig. 13. Total loss breakdown by circuit topologies 


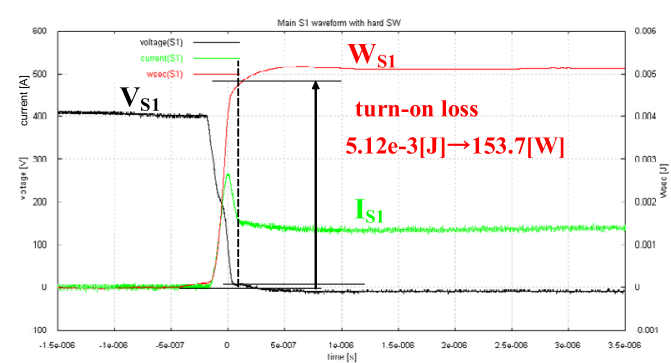

(a) Hard SW: $\mathrm{S}_{1}$ turn-on

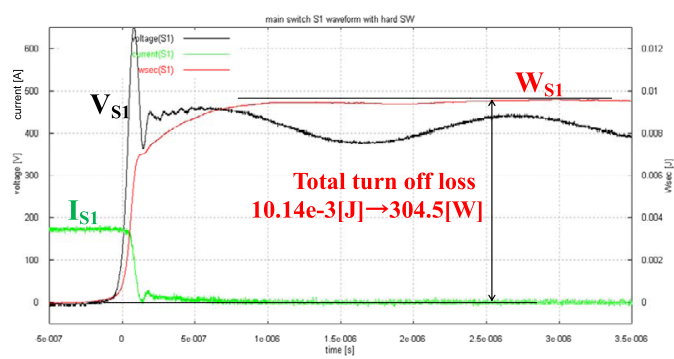

(c) Hard SW: $\mathrm{S}_{1}$ turn-off

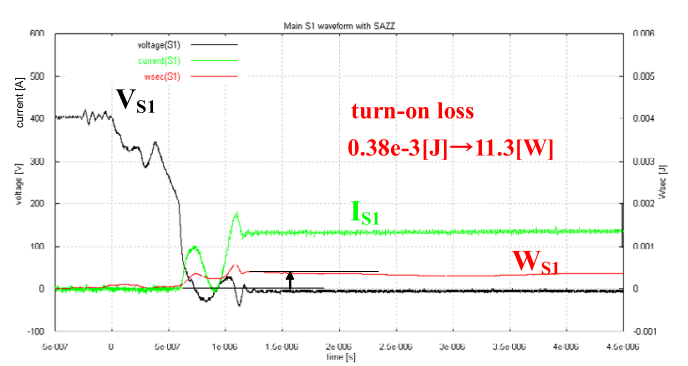

(b) Partial SAZZ: $\mathrm{S}_{1}$ turn-on

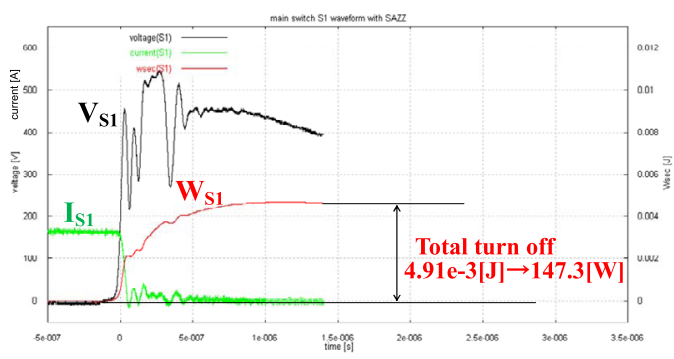

(d) Partial SAZZ: $\mathrm{S}_{1}$ turn-off

Fig. 14. Loss breakdown comparison of main switch $\mathrm{S}_{1}$ between Hard $\mathrm{SW}$ and partial SAZZ

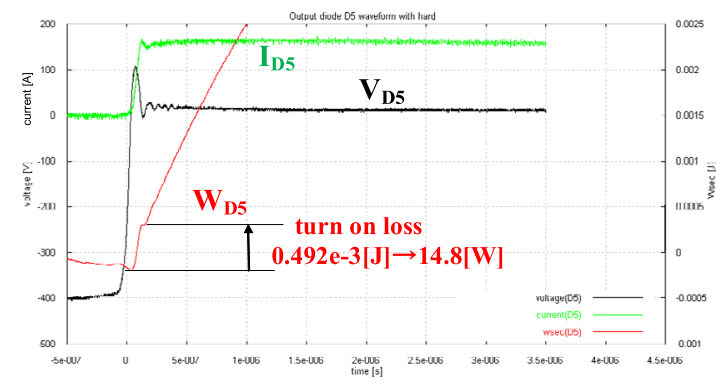

(a) Hard SW: Output diode $\mathrm{D}_{5}$ turn-on

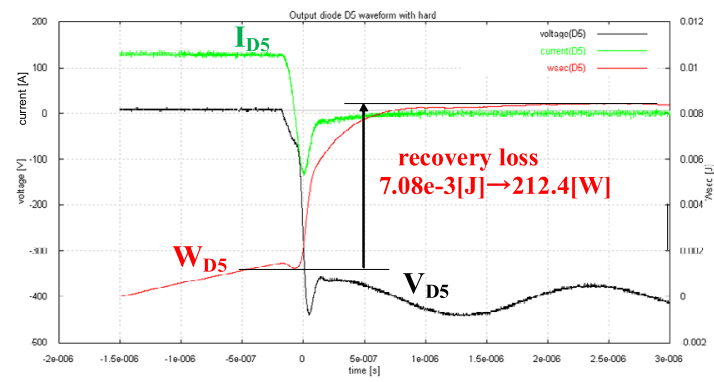

(c) Hard SW: Output diode $\mathrm{D}_{5}$ turn-off

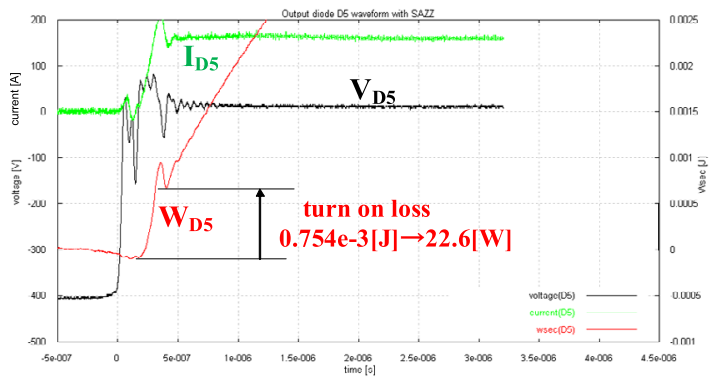

(b) Partial SAZZ: Output diode $\mathrm{D}_{5}$ turn-on

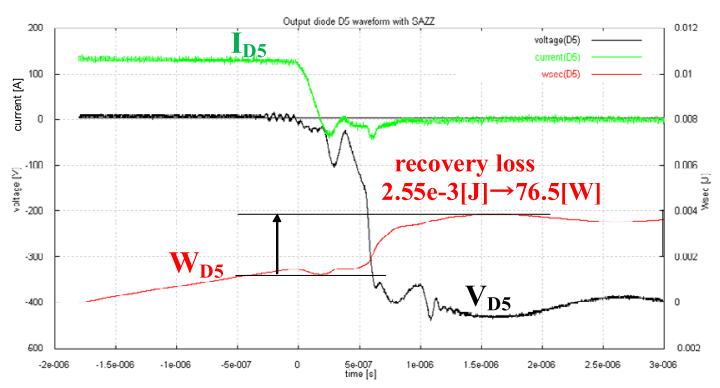

(d) Partial SAZZ: Output diode $\mathrm{D}_{5}$ turn-off

Fig. 15. Loss breakdown comparison of output diode $\mathrm{D}_{5}$ between Hard $\mathrm{SW}$ and partial SAZZ

with $71.6 \%$ reduction. Auxiliary circuit based on Partial SAZZ topology operates minimum just before turn-on during switching operation of main switch $S_{1}$. As a result of comparison of main circuit switching loss between Hard SW and Partial SAZZ, efficiency improvement by $1.82 \%$ between Hard SW and Partial SAZZ proved to be mainly due to $61.2 \%(299.6 \mathrm{~W})$ reduction of switching loss with main switch $\mathrm{S}_{1}, 27.8 \%(135.9 \mathrm{~W})$ reduction of recovery loss with output diode $\mathrm{D}_{5}$ and $11 \%(54 \mathrm{~W})$ reduction of unknown factor loss.

Figures 14 and 15 show the evidence of this findings mentioned above. Turn-on loss of main switch $\mathrm{S}_{1}$ decreases $153.7 \mathrm{~W}$ (Hard SW) $\rightarrow 11.3 \mathrm{~W}$ (Partial SAZZ) with $92.6 \%$ reduction of $142.4 \mathrm{~W}$ as shown in Fig. 14(a), (b). Turn-off loss of main switch $\mathrm{S}_{1}$ decreases $304.5 \mathrm{~W}$ (Hard
$\mathrm{SW}) \rightarrow 147.3 \mathrm{~W}$ (Partial SAZZ) with $51.6 \%$ reduction of 157.2 $\mathrm{W}$ as shown in Fig. 14(c), (d). Total reduction of switching loss with main switch $\mathrm{S}_{1}$ is $299.6 \mathrm{~W}$. Recovery loss of output diode $\mathrm{D}_{5}$ decreases $212.4 \mathrm{~W}$ (Hard SW) $\rightarrow 76.5 \mathrm{~W}$ (Partial SAZZ) with $64.0 \%$ reduction of $135.9 \mathrm{~W}$ as shown in Fig. 15(c), (d). Unknown factor loss decreases $309.27 \mathrm{~W}$ $($ Hard SW) $\rightarrow 255.54$ W (Partial SAZZ) with $17.4 \%$ reduction of

53.73 W as shown in Fig. 13. Moreover as a result of breakdown measurement, total auxiliary circuit loss of $41.3 \mathrm{~W}$ by Partial SAZZ is mainly composed of auxiliary switch $S_{2}$ of $18 \mathrm{~W}$ and snubber diode $\mathrm{D}_{1}$ loss of $23 \mathrm{~W}$.

\section{Conclusion}

In this paper 2 types of circuit topologies such as Hard SW 
and Partial SAZZ, are compared as high power chopper. Soft switching can principally reduce switching loss with conventional Hard SW. However the increase of auxiliary circuit loss in order to obtain function of soft switching formula impedes loss reduction as expected. As shown, Partial SAZZ topology is effective to reduce IGBT turn off loss at fairly high power range operation. Significant contribution in high power boost chopper is partial soft switching method by ZVS without over-elimination. As can be seen, at $30 \mathrm{~kW}$ Partial SAZZ was $1.82 \%$ higher than Hard SW, from $95.6 \%$ to $97.42 \%$ and was higher efficiency over whole power region. Optimization of LC parameter, reliability and efficiency on Partial SAZZ topology were confirmed.

\section{References}

( 1 ) H. Ohashi: "Power electronics innovation with next generation advanced power devices", Proc. of Telecommunications Energy Conference, INTELEC 2003, pp.9-13 (2003)

( 2 ) H. Ohasi: "Recent Power Devices Trend", T. IEE Japan, Vol.12, No.3, pp.168-171 (2002) (in Japanese)

( 3 ) J.W. Kolar, U. Drofenik, J. Biela, M.L. Heldwein, H. Ertl, T. Friedli, and S.D. Round: "PWM Converter Power Density Barriers", Proc. of Power Conversion Conference, PCC 2007, pp.9-29 (2007)

( 4 ) Y. Tsuruta, M. Pavlovsky, and A. Kawamura: "State-of-the-Art High Power Density and High Efficiency DC-DC Chopper Circuits for HEV and FCEV Applications", Proc. of International Power Electronics and Motion Control Conference, EPE-PEMC 2008, pp.7-20 (2008)

( 5 ) S. Waffler and J.W. Kolar: "A novel low-loss modulation strategy for highpower bi-directional buck+boost converters", Proc. of International Conference on Power Electronics, ICPE 2007, pp.889-894 (2007)

( 6 ) W. Yu and J.-S. Lai: "Ultra High Efficiency Bidirectional DC-DC Converter with Multi-Frequency Pulse Width Modulation", Proc. of IEEE The Applied Power Electronics Conference and Exposition, APEC 2008, pp.1079-1084 (2008)

( 7 ) W. Yu, H. Qian, and J.-S. Lai: "Design of High-Efficiency Bidirectional DCDC Converter and High-Precision Efficiency Measurement", Proc. of the $34^{\text {th }}$ Annual Conference of the IEEE Industrial Electronics Society, IECON 2008, pp.685-690 (2008)

( 8 ) B. Eckard, A. Hofman, S. Zeltner, and M. Maerz: "Automotive Powertrain DC-DC Converter with $25 \mathrm{~kW} / \mathrm{dm}^{3}$ by using SiC Diodes", $4^{\text {th }}$ International Conference on Integration of Power Electronics System, pp.1-6 (2006)

(9) M. Hirakawa, M. Nagano, Y. Watanabe, K. Andoh, S. Nakatomi, and S. Hashino: "High Power Density DC/DC Converter using the Close-Coupled Inductors", Proc. of the $1^{\text {st }}$ IEEE Energy Conversion Congress and Exposition, ECCE 2009, pp.1760-1767 (2009)

(10) K. Maikawa, Y. Tsuruta, and A. Kawamura: "Soft Switching Chopper Circuit for high power application", IEEJ/JIASC 2003, No.1-101, pp.477-478 (2003) (in Japanese)

(11) Y. Tsuruta and A. Kawamura: "Proposed of 98.5\% High Efficiency Chopper Circuit QRAS for the Electric Vehicle and the Verification", T. IEE Japan, Vol.125-D, No.11, pp.977-987 (2005) (in Japanese)
(12) Y. Tsuruta, Y. Ito, and A. Kawamura: "The proposal of SAZZ chopper circuit and test verification by means of the preceding fabrication", 2005 National Convention Record, No.4-045, pp.71-72 (2005) (in Japanese)

(13) Y. Tsuruta, M. Bando, Y. Ito, and A. Kawamura: "A New Circuit Geometry SAZZ for an EV Drive Application", IEEE Industry Applications Conference $41^{\text {st }}$ Annual Meeting, IAS 2006, IAS54p5, pp.1-6 (2006)

(14) Y. Tsuruta, M. Pavlovsky, and A. Kawamura: "Very High Efficiency AZZ Chopper Using High Speed IGBT", 2009 IEEE 6th International Power Electronics and Motion Control Conference - ECCE Asia -, IPEMC 2009, OS8, pp.573-579 (2009)

(15) Y. Tsuruta, M. Pavlovsky, and A. Kawamura: "Improvement of Mid-Power SAZZ Chopper for Very High Efficiency", IEEJ/JIASC 2009, No.1-139, pp.667-670 (2009) (in Japanese)

(16) Y. Tsuruta and A. Kawamura: "Verification of Efficient Operation for High Power DC Chopper", Proc. of IEEE 8th International Conference on Power Electronics-ECCE Asia, ICPE 2011, WeG4-4, pp.1286-1293 (2011)

(17) Y. Tsuruta and A. Kawamura: "Evaluation of Efficiency Sensitivity Analysis on High Power Chopper", IEEJ/JIASC 2013, No.1-19, pp.121-124 (2013) (in Japanese)

Yukinori Tsuruta (Member) received the B.S., M.S., and Ph.D. de-

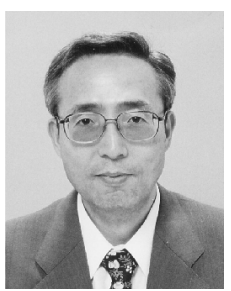
grees in electrical engineering from Yokohama National University, Yokohama, Japan, in 1975, 1977, and 2006, respectively. From 1977 to 2003, he was with Toshiba Corporation, Tokyo, Japan, working with the Design and Development Section of Power Converter Equipment as a Specialist Engineer in the Fuchu Works. He is currently with Yokohama National University as a Postdoctoral Fellow and a Lecturer (Non-Full-time). His research interests are highfrequency converter, soft-switching converter and chopper for EV drive system

Atsuo Kawamura (Fellow) was born in Yamaguchi, Japan, in De-

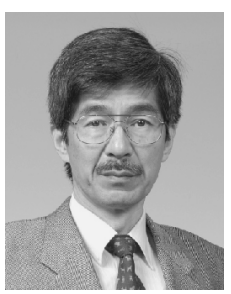
cember 1953. He received the B.S.E.E., M.S.E.E., and $\mathrm{Ph} . \mathrm{D}$. degrees in electrical engineering from the University of Tokyo, Tokyo, Japan, in 1976, 1978, and 1981, respectively. In 1981, he was with the Department of Electrical and Computer Engineering, University of Missouri, Columbia as a Postdoctoral Fellow, where he was an Assistant Professor from 1983 to 1986. Since 1986, he has been with the Division of Electrical and Computer Engineering, Yokohama National University, Yokohama, Japan, where he was first an Associate Professor and later became a Professor in 1996. His research interests include power electronics, digital control, electric vehicles, robotics, train traction control, etc. Dr. Kawamura is a member of the Institute of Electrical Engineers of Japan (IEE of Japan), Robotics Society of Japan, and several other organizations. He was the conference Chairperson of IPEC-SapporoECCE-Asia in 2010. He received the IEEE IAS Transactions Prize Paper Award in 1988, the Prize Paper Award of IEE of Japan in 1996, IEEE IES Transactions Best Paper Awards in 2001 and 2002, and EPE-PEMC Award in 2008 . 